TILTAI, 2014, 3, 1-16, ISSN 1392-3137 (Print), ISSN 2351-6569 (Online)

\title{
INTELEKTINIS KAPITALAS KAIP MOKSLO IR VERSLO BENDRADARBIAVIMO STIPRINIMO POTENCIALAS
}

\author{
Rita Vaičekauskaitė \\ Klaipédos universitetas
}

\begin{abstract}
Anotacija
Intelektinis kapitalas (IK) ir kitos šiandien populiarios technologijų perdavimo, žinių valdymo koncepcijos XX a. 8-ajame dešimtmetyje pirmiausia aktualizuotos verslo pasaulyje, siekiant parodyti ịmonių konkurencinio pranašumo didinimo kryptị žinių visuomenèje. Intelektinio kapitalo identifikavimu siekta parodyti, kad verslo įmonèms aktualūs idèjų ir žinių kūrimo procesai, o ne tik materialinių ir finansinių vertybių gausinimas bei apskaita. Intelektinio kapitalo klausimas universitetuose iki šiol neaktualizuotas taip, kaip verslo įmonèse, laikantis transcendentinio filosofinio požiūrio, kuris IK traktuoja kaip organišką universiteto veiklos bruožą. Tačiau šiuolaikinèje visuomenèje universitetai turètų išmokti transformuoti IK ị konkurencinį, verslumo ir inovacijų potencialą, todèl svarbu IK konceptualizuoti vadybinèmis kategorijomis. Straipsnyje plètojama mokslinė diskusija, kuri skatina intelektinị kapitalą suvokti ne kaip fiksuotą rodiklį, o kaip organizacijos santykio su žiniomis koncepciją. Be to, intelektinio kapitalo koncepcija sukurta žinių visuomenèje, tačiau inovacijas kuriančioje visuomenėje svarbu iš naujo apsvarstyti jos reikšmę. Šiame straipsnyje siekiama atskleisti intelektini kapitalą kaip mokslo ir verslo bendradarbiavimo stiprinimo potencialą.

PAGRINDINIAI ŽODŽIAI: intelektinis kapitalas, mokslas, verslas, bendradarbiavimas, konkurencingumas.
\end{abstract}

\begin{abstract}
Intellectual capital (IC), technology transfer and knowledge management gained a high topicality in knowledge-based economy. The aforementioned concepts emerged in a business world to show competitive advantage of enterprise in a knowledge-based economy. Identification of IC was oriented to demonstrate that enterprises are concerned with knowledge creation and not solely with financial accounting. On the contrary, IC is an organic entity of university life. However, in nowadays society universities should transform IC into competitive advantage; therefore, it is important to evaluate IC at universities using management categories. The article calls for scientific discussion that encourage understanding of IC as organization's relationship with knowledge concept instead of fixed index. Moreover, IC concept is developed in a knowledge-based economy context, but now-days we need reconsider IC meaning in innovations context. The article aim to reveal the potential of IC to strengthen cooperation between science and business.
\end{abstract}

KEY WORDS: intellectual capital, science, business, cooperation, competitive.

DOI: http://dx.doi.org/10.15181/tbb.v68i3.881

\section{Ivadas}

Intelektinio kapitalo idèja XX a. 8-ajame dešimtmetyje aktualizuota verslo pasaulyje, siekiant parodyti galimas įmonių konkurencinio pranašumo didinimo kryptis žinių visuomenejje. IK svarba konkurencingumui neleidžia abejoti tuo, kad 
verslo įmonėse intelektinis kapitalas sudaro iki 85 proc. visos jos ekonominès vertès (Walsh, 2008, cit.: Mačerinskienè, Bartusevičienè, 2012, p. 96). Nors žinios yra svarbi intelektinio kapitalo dedamoji, jos negali teikti pridètinès vertès kaip mechaniška suma. Tačiau žinios, kaip organiškas įmonès veiklos darinys, kuria organizacijos intelektini kapitalą. IK klausimas universitetuose iki šiol taip stipriai kaip verslo ịmonėse neaktualizuotas, nes laikytasi transcendentinio filosofinio požiūrio, kuris IK traktuoja kaip neatskiriamą universiteto veiklos bruožą. Tačiau kaip įvardyti universiteto intelektinị kapitalą, remiantis vadybinėmis kategorijomis? Tai didelè problema. Anot V. Gižienès ir V. Barkausko (2010), visi intelektinio kapitalo vertinimo modeliai pirmiausia orientuoti ị verslo įmonę, jos apskaitą, valdymą. Tik pastaruoju metu pasirodo mokslinių darbų, kuriuose analizuojama, kaip intelektinio kapitalo vertinimas privačiose įstaigose gali būti pritaikomas universitetuose (Canibano, Sanchez, 2009). Intelektinio kapitalo vertinimas galètu padèti universitetams tobulinti valdymą ir reprezentuoti savo mokslinị ịdirbị bei potencialą (Sanchez et al, 2009). Vis dèlto kyla pavojus, kad IK vertinimai bus pripildyti nereikšmingų ar perteklinių rodiklių (Canibano, Sanchez, 2009). Intelektinis kapitalas turètų būti daugiau negu statistinių duomenų rinkinys, tai yra nuoroda ị organizacijos potencialą, jos dabartinę ir ateities vertę. P. N. Rastogi (2003) teigimu, intelektinis kapitalas - tai holistinis, arba metalygio, organizacijos gebèjimas koordinuoti, suderinti ir pritaikyti jos žinių išteklius, kuriant vertę ir siekiant ateities vizijos. Tam, kad būtų galima efektyviau planuoti ateities galimybes ir priimti ilgalaikius strateginius sprendimus, būtina ịvertinti intelektinị kapitalą (Andriessen, 2007), nes naujųų verslo modelių samprata ir tikslai nurodo, kad „daug svarbesné už pelną tapo įmonès verté“ (Laurs, 2013, p. 70).

L. Edvinsson ir M. Malone (1997) intelektinị kapitalą apibūdino kaip žinių, patirties, organizacinių technologijų, santykių su klientais bei profesionaliu igūdžių valdymą, kuris yra konkurencinio pranašumo kūrimo pagrindas (cit.: Mačerinskienè, Bartusevičienè, 2012, p. 97). IK yra labai populiari ir sparčiai plètojama koncepcija, tačiau, anot K. Chaharbaghi ir S. Cripps (2006), ją artikuliuojant atsiranda nemažai retorikos ir ideologijos, per mažai kritinio diskurso, todèl trūksta tyrimais pagrịstų ịrodymų, kad IK vertinimas tiesiogiai veikia įmonės veiklą ar jos konkurencingumą. IK koncepcija išplètota žinių ekonomikos kontekste, tačiau iš šių dienų perspektyvos svarbu ją diskutuoti inovacijų aspektu.

Atrodo, kad mokslo ir verslo bendradarbiavimui šiuolaikinèje visuomeneje yra sukurtos svarios prielaidos. Tačiau šiandien stebime situaciją, kad mokslas ir verslas Lietuvoje bendradarbiauja lètai. Optimistiškai nuteikia, kai spaudoje skaitome geriausio vadovo Lietuvoje poziciją: „Investuoti ị mokslą turètų net smulkios 
imonès"1. Patirtis rodo, kad universitetui neužtenka viešai siūlyti savo paslaugų, kad jos būtų perkamos. Aktualus klausimas, kaip suformuoti siūlomų paslaugų poreikį. Gyvename vartotojiškoje visuomeneje, kurioje sėkmė lydi tuos, kurie geba ne tik pagaminti gerą prekę, suteikti gerą paslaugą, bet ir moka jas pasiūlyti, suformuoti jų poreikị. S. M. Goldstein ir kolegų (2002) požiūriu, organizacijai svarbu siūlyti ne tik specifines, bet ir konceptualias paslaugas. R. Barnett (2013) požiūriu, šiuolaikiniam universitetui labiausiai trūksta vaizduotès. Ši konceptuali R. Barnett ịžvalga labai aktuali, kalbant apie mokslo ir verslo bendradarbiavimą inovacijų kontekste. Nors Lietuva inovacijų švieslenteje pakilo ị nuosaikiujų inovatorių gretas ${ }^{2}$, tačiau pagal ekonominį inovacijų poveikị užima paskutinę vietą ES (Lietuvos mokslo būklès apžvalga, 2014, p. 7). Tai reiškia, kad mokslo ir verslo bendradarbiavimui trūksta konceptualumo. Šioje vietoje svarbu pažymėti: kad ir koks būtų technologinis atradimas, jis nebus laikomas inovacija, jei nelems ekonominio efekto (Melnikas et al., 2011, p. 86). Intelektinio kapitalo artikuliavimas suteikia galimybę universitetams kalbèti apie paslaugas konceptualiai, aiškiai nurodant inovacijų perspektyvas. Sistemingo ir ilgalaikio bendradarbiavimo svarba pažymima kalbant apie inovacijų kūrimą ir plètrą.

Straipsnio tikslas - atskleisti intelektini kapitalą kaip mokslo ir verslo bendradarbiavimo puoselèjimo potencialą.

Tyrimo metodai: sisteminè teorinès literatūros analizè, tyrimų duomenų metaanalizè. Straipsnio autorès pasirinkta metodologinè prieiga orientuota i ,,metodinị permatymą“", kaip sutelkto mąstymo ir stebejjimo praktiką, kuri nurodo ị ¡žzalgas, kuriomis remiantis tikslinami reikšmių susidarymo procesai ir jų kontekstinès sąsajos (Valantiejus, 2007).

\section{Intelektinio kapitalo koncepcija inovacijų kontekste}

Intelektinio kapitalo termino pirminė intencija - suteikti nuorodą ị tai, kad intelekto nereikètų vertinti kaip statiško, determinuoto dalyko, o kaip socialinị procesą, tam tikrą ideologini imperatyvą. Toks atviras ir platus konceptualizavimas leido ịvairiai, kompleksiškai modeliuoti idèją. Galbūt dèl to, intelektinio kapitalo koncepcija iki šiol neturi unifikuoto turinio. IK yra tai, kas kuria organizacijos produktų ir jos paslaugų vertę. Dauguma tyrinėtojų IK apibrèžia kaip trijų dedamujų žmogiškojo, struktūrinio ir vartotojų kapitalo - sąveiką (Stewart, 1997). Kai kurie

\footnotetext{
Prieiga internete: http://www.delfi.lt/mokslas/mokslas/geriausias-vadovas-lietuvoje-investuotii-moksla-turetu-net-smulkios-imones.d?id=61860035\#ixzz3CR0BeLGK

2 Prieiga internete: http://ec.europa.eu/enterprise/policies/innovation/files/ius/ius-2014_en.pdf, p. 11.
} 
autoriai siūlo smulkiau diferencijuoti IK turinį, tačiau tradicinis yra trijų dedamụjų intelektinio kapitalo struktūros modelis:

- Žmogiškieji ištekliai (arba darbuotojų kapitalas) apima individų žinias, kompetencijas ir įgūdžius, t. y. darbuotojų individualios žinios, kurias jie, pasibaigus darbo dienai, išsineša su savimi. Tai vadinamosios neišreiškiamos žinios. Manoma, kad apie 90 proc. visų individo turimų žinių pasireiškia neišreikštosios informacijos forma, todèl organizacijoms, siekiančioms padidinti savo efektyvumą, svarbu gausinti išreikštąsias žinias. Organizacijos pakankamai dèmesio ir investicijų turètų skirti darbuotojų kvalifikacijai - skatinti ją kelti. Darbuotojų ištekliai apima jų vertybes ir kultūrą.

- Struktūriniai ištekliai (arba organizacinis kapitalas) atskleidžia organizacijos kultūrą, valdymo strategiją, mechanizmus, kurių paskirtis padèti darbuotojams optimaliai igyvendinti jiems paskirtas užduotis, kurios vèliau tampa intelektiniu kapitalu (t. y. organizacijos informaciniai ištekliai ir žinios, sutelkti duomenų bazèse, procesų aprašuose, dokumentuose ir pan.) (Mačerinskienè, Bartusevičienè, 2012, p. 97). Struktūrinis kapitalas yra tai, kas lieka darbuotojams palikus darbo vietą, t. y. technologijos, procesai ir sistemos (Roos et al., 1997). R. Mikulėnienė (2000) struktūrinị kapitalą ịvardija kaip svarbiausią prielaidą darbuotojų kapitalui virsti intelektiniu kapitalu. Infrastruktūros priemonès turi veikti kaip tinklas, padedantis išsaugoti žinias, kuriomis darbuotojai vèliau galès keistis tarpusavyje. Be to, tinklas turètų užtikrinti ir darnų bendradarbiavimą su kitomis įmonemis bei informacijos naudojimą komerciniams tikslams. Šia prasme intelektinis kapitalas yra artimas žinių valdymo koncepcijai ir nurodo, kad įmonei neužtenka tik samdyti geriausius šios srities specialistus, nesukūrus sistemos, kurioje dalijamasi žiniomis. T. A. Stewart (1997) IK apibrèžè kaip „naudingų žinių paketą“. Tačiau žinių vadybos svarba intelektiniam kapitalui neturètų būti perdètai sureikšminama. Svarbūs yra socialinis palaikymas ir organizacinè kultūra (Sanchez-Canizares, Munoz, Lopez-Guzman, 2007).

- Ryšių ištekliai (arba vartotojų, ryšių kapitalas) rodo organizacijos tinklą, santykius su klientais, vartotojais, remejjais, partneriais ir pan. Kai kurie tyrinètojai ryšių kapitalą laiko struktūrinio kapitalo dalimi, tačiau daugelis tyrejų ji linkę išskirti kaip atskirą IK dedamąją. Vartotojiškoje visuomeneje svarbiausia yra ne prekè ar paslauga, kurią ịsigyja klientas, bet ịspūdis. Kai kurie tyrinètojai siūlo skirti dvi santykių kapitalo 
dalis - partnerysčiu ir vartotojų kapitalas. F. Susan (2012) aktualizuoja specifinę ryšių kapitalo dedamąją dalị eWOM (angl. electronic word of mouth) - tai vartotojų internetu platinama informacija, kurios itaka įmonių veiklos efektyvumui sparčiai auga (cit.: Mačerinskienė, Bartusevičienè, 2012, p. 97).

Vis dèlto IK neturètų būti suprantamas kaip paminètų trijų struktūrinių komponentų mechaninè suma, o kaip jų tarpusavio sąveikos ekosistema, kurios jungiamoji grandis yra socialinis kapitalas. Socialinis kapitalas apima santykius, nuostatas, vertybes, kurie kreipia žmonių tarpusavio santykius kurti ekonominę ir socialinę gerovę. Socialinis kapitalas yra organizacijos žmogiškujų ryšių dedamoji, kuri skatina darbuotojus dalintis žiniomis, produktyviai dirbti. Tačiau socialinis kapitalas neturètų būti tapatinamas su ryšių (arba vartotojų) kapitalu. Anot M. Khalique (2011), per pastarajị dešimtmetị išplètotas socialinio ir dvasinio kapitalo (Ismail, 2005) koncepcijas aktualizuojamos žmogiškojo kapitalo emocinè ir vertybių dedamosios. Socialinis ir dvasinis kapitalas yra svarbūs siekiant išvengti ribotumų, kad IK vertinimas netaptų per daug formalizuotas, per daug orientuotas ị rinkodaros technologijų padiktuotus sprendimus.

Socialinis kapitalas yra reikšmingas inovacijų kontekste. Inovacijų organizacijose esminiu plètros veiksniu laikomi ne tiek konkretūs MTEP rodikliai, kiek kokybiškai pasikeitusi žmonių mąstysena ir elgsena, organizacijos gebejjimas susidoroti su rizikos veiksnių neapibrèžtumu, žinių, kaip visuotinès gèrybès, nepanaudojamumu (Melnikas ir kt., 2011, p. 213, 245). Žinių ekonomikos plètra aktualizuojant inovacijas, formuoja naują inovacijų kultūros (The Culture of Innovations and the Building <...>, 2003) reiškinị. Socialinis kapitalas yra veiksnys, igalinantis kurti ir puoselèti inovacijų kultūrą.

\section{Intelektinio kapitalo vertinimo ypatumai verslo įmonèse ir universitetuose}

Skiriamos keturios pagrindinès intelektinio kapitalo vertinimo modelių kategorijos (Chua, Gohas, 2008, cit.: Mačerinskienè, Bartusevičienė, 2012, p. 100):

1. Tiesioginis intelektinio kapitalo metodas (angl. Direct Intellectual Capital-DIC): identifikuoja nematerialų turtą ir nustato jo piniginę vertę.

2. Rinkos kapitalizacijos metodas (angl. Market Capitalisation-MC): nustato intelektinio kapitalo vertę, ịvertindamas skirtumą tarp įmonès rinkos ir balansinès vertès. 
3. Turto pelningumo metodas (angl. Return On Assets - ROA): įvertina intelektinį kapitalą, remiantis įmonès pelno, materialaus turto ir pramonès šakos turto pelningumo vidurkiu per numatytą laiko vienetą.

4. Suderintu vertinimo rodiklių metodas (angl. balanced scorecard methodBSC): identifikuoja nematerialius išteklius panašiu principu kaip ir tiesioginio intelektinio kapitalo metodas, skiriasi tuo, kad nevertina intelektinio kapitalo pinigine išraiška.

Intelektinio kapitalo vertinimo būdai gali būti sugrupuoti ị dvi kategorijas (Sveiby, 2001; Pike, Roos, 2000): tie, kurie įvertina intelektinį kapitalą pinigine verte, ir tie, kurie piniginio intelektinio kapitalo vertinimo netaiko. Nemažai diskutuojama dèl IK vertinimo pinigine išraiška, bet konsensusas nelabai pasiekiamas.

Pastebima tendencija, kad modeliai kuriami tam tikriems iš anksto numatytiems tyrimo objektams: SI CAP modelis (Ramirez, 2010), skirtas tik viešojo sektoriaus analizei; nacionalinio intelektinio kapitalo modelis (Bontis, 2000) intelektiniam kapitalui vertinti nacionaliniu lygmeniu ir t. t. Tai patvirtina, kad intelektinio kapitalo koncepcija dar nėa pastovi ir skirtinguose sektoriuose ji vertinama nevienodai (cit.: Mačerinskienè, Bartusevičienè, 2012, p. 100). Anot K. Chaharbaghi ir S. Cripps (2006), IK sunkiai išmatuojamas skaičiais, kurie leistų nustatyti, sustiprèjo ar susilpnèjo įmonès IK, be to, trūksta tyrimais pagrịstų ịrodymų, kad IK vertinimas teigiamai veikia įmonès veiklą ar jos konkurencingumą.

Kaip minèta, intelektinio kapitalo vertinimas universitetuose yra problema, nes vertinimo modeliai pirmiausia orientuoti ị verslo įmonę, jos apskaitą, valdymą (Gižienè, Barkauskas, 2010). Kita vertus, verslo įmonès IK vertinimo modelių taikymas universitete galètų padèti tobulinti aukštojo mokslo ir studijų valdymą. B. Meihami ir J. Karami (2014) požiūriu, universitetų pastangos nustatyti IK teigiamai veikia organizacijos finansinę, mokslinę ir studijų veiklą.

J. Papula ir J. Volna (2011) teigimu, IK valdymas universitete yra žinių vadybos objektas ir viena svarbių žinių vadybos plètros gairių (1 pav.). Tačiau IK vertinimas netapatus žinių vadybai, nes rodo organizacijos žinias, kurios kuria pridètinę vertę. 


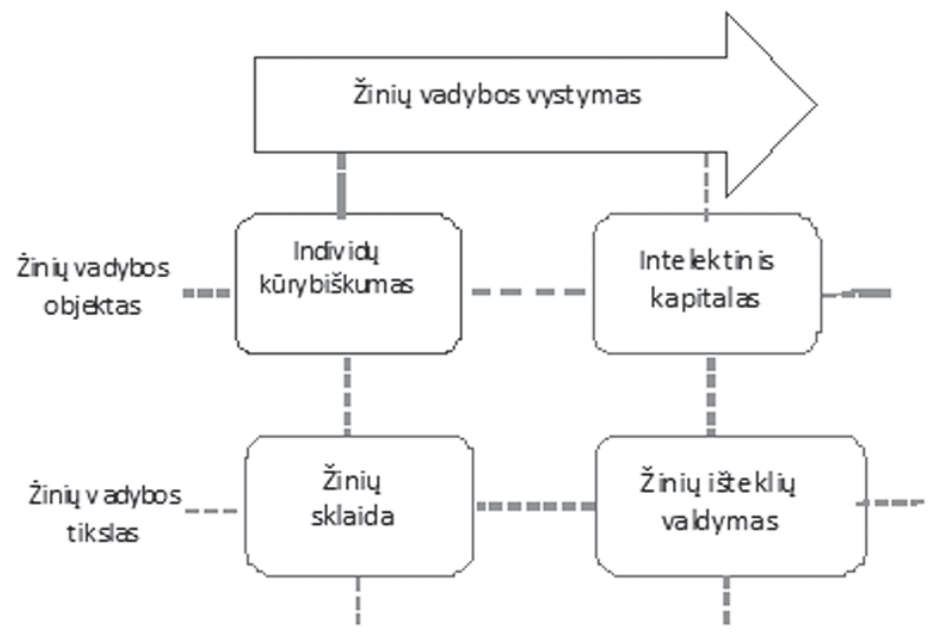

1 pav. Intelektinis kapitalas žinių vadybos kontekste

Šaltinis: Papula, Volna, 2011, p. 499

Pastaruoju metu intensyviai diskutuojama, kaip universitetų intelektiniam kapitalui vertinti galima pritaikyti ir kai kuriuos esamus modelius (Sanchez et al., 2009; Elena, 2009; Ramirez Córcoles, 2013), ypač tuos, kurie pagrindinị dèmesi kreipia ị nematerialiujuc išteklių (angl. intangible resources) vertinimą, tokie kaip „,nematerialiųjų išteklių stebėsena“ (angl. Intangible Asset Monitor; Sveiby, 1997, 2001). Tačiau pripažįstama, kad šiandieniniai modeliai tik iš dalies gali padèti atskleisti universiteto IK vertinimo specifiką. Pastaruosius du dešimtmečius aktyviai vykdyti tarptautiniai (MERITUM, 2002; RICARDIS, 2006) ir nacionaliniai („Intellectual Capital Report 1999-2004“, Austrija; INGENIO, 2002 ir PCI, 2003, Ispanija) projektai, rengtos studijos (Observatory of the European University, 2004-2006), analizuoti intelektinio kapitalo vertinimo universitetuose ypatumai ir kurti tam tinkami modeliai. Tai reiškia, kad universitetų IK vertinti sudarytos atitinkamos galimybės, o jam plètoti susiklosčiusi palanki terpé, nes per pastaruosius metus universitetai įdiegė kokybès vadybos sistemas, kurios leidžia sistemingai valdyti IK vertinimui aktualius duomenis. Be to, kokybės vadybos sistema ịgalina sistemiškai valdyti IK, tai apima planavimą, igyvendinimą, vertinimą ir tobulini- 
mą. Kokybės vadybos sistemos diegimas universitetuose parodè, kad verslo sektoriuje naudojami instrumentai gali padèti gerinti universitetų veiklos vadybą.

\section{Diskusija}

2014 metais MOSTA atliktoje Lietuvos mokslo būklès apžvalgoje konstatuota, kad mokslo ir verslo bendradarbiavimas išlieka silpnas (Lietuvos mokslo būklès apžvalga, 2014, p. 11). 2009-2011 m. Lietuvos MSI iš šalies įmonių gavo 9,6 mln. litų vertės užsakymų darbams, kuriuos LMT pripažino kaip MTEP. Užsakymų apimtys 2011 m. buvo ketvirčiu mažesnès nei 2009 m. 2010-2012 m. didžiausia technologinių novatorių dalis (daugiau nei 30 proc.) bendradarbiavo su įrangos tiekejjais, t. y. iš tiekẻjų nusipirko technologini sprendimą. Mažiausia technologinių novatorių dalis (11 proc.) bendradarbiavo su valstybės mokslinių tyrimų ịstaigomis (Lietuvos mokslo būklès apžvalga, 2014, p. 11). Siekiant puoselèti mokslo ir verslo bendradarbiavimą, būtina tam tikra materialinè bazè ir materialinis interesas. Pamatinę materialinę mokslo ir verslo bendradarbiavimo bazę sukuria valstybės remiamos programos. Lietuvoje yra nemaža tokių programų ịvairové ir jos nuolat tobulinamos, atsižvelgiant tiek ị universitetų, tiek ị verslo poreikius. Tačiau svarbu pripažinti, kad varomoji bendradarbiavimo jẻga yra idejos ir jomis grindžiamos vizijos, ypač kalbant apie ilgalaikes ir perspektyvias verslo investicijas. Naujausios tendencijos aiškiai rodo, kad idejos, o ne tik pinigai tampa pagrindiniu verslo sėkmès veiksniu. „Žmonès, kuriems visų pirma rūpi gera idèja, sukuria geresnị produktą ir laimi finansiškai“ (Laurs, 2013, p. 28). Todèl intelektinio kapitalo vertinimas yra svarbus veiksnys, siekiant kurti darnią, inovacijų perspektyvomis grindžiamą mokslo ir verslo bendradarbiavimo aplinką (Reporting Intellectual Capital to augment research $\langle\ldots>$, 2006; Elena, 2009). Verslo pasaulyje formuojasi tendencija, kai žinios apie bendroves intelektinį kapitalą lemia svarbius investuotojų sprendimus ir bendradarbiavimo susitarimus (Williams, 2001). Kuriant inovacijas svarbus ilgalaikemis perspektyvomis grindžiamas bendradarbiavimas (The Culture of Innovations and the Building < ... > 2003). Be to, inovacijos kuriamos ir diegiamos labai kompleksinèse aplinkose. Moksliniai tyrimai rodo, kad žiniomis grindžiamos inovacijos sėkmingai kuriamos ne monopolinèje terpèje, o sąveikaujant daugeliui veikejjų: mokslininkams, vadybininkams, inovatyvioms įmonėms, kompetentingiems žmonėms, informacinėms infrastruktūroms (Melnikas et al, 2011, p. 183).

Pirminis įspūdis inovacijas klaidingai sieja su atsitiktiniu eksperimentavimu, 
kurị dažnai lydi fatališkos sėkmės veiksnys, siekiant naujovių. Tuo tarpu inovacijų kūrimas yra ilgalaikis ir sistemingas procesas. Inovacijos versle - tai ị rizikingus pokyčius orientuotas procesas, kai žinios kultūrinejje aplinkoje paverčiamos konkurencingais produktais ar paslaugomis (Gečas, Jucevičius ir kt., 2007; cit.: Melnikas et al, 2011, p. 87). Intelektinio kapitalo valdymas ir vertinimas galètų padèti identifikuoti žinias ir idejjas, kurių potencialas virsti konkurencingais produktais ir paslaugomis yra didžiulis (2 pav.).

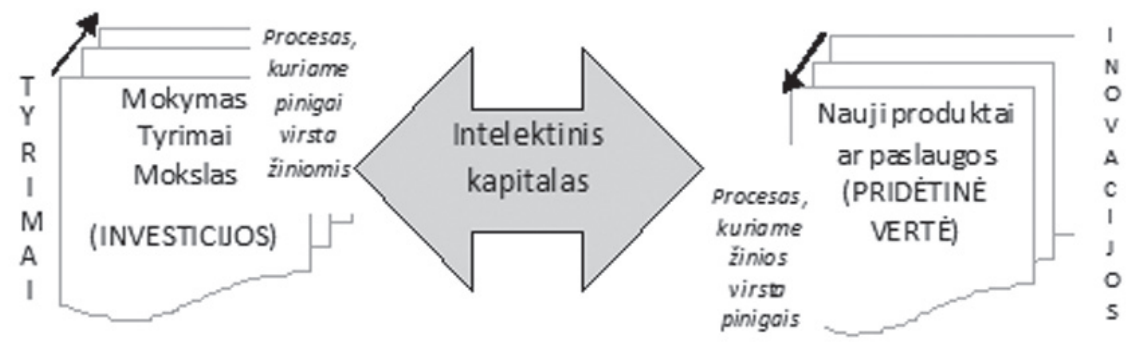

2 pav. Intelektinis kapitalas sąveikaujant tyrimams ir inovacijoms Šaltinis: Melnikas ir kt., 2011, p. 85, modifikuota straipsnio autorès

Lietuvoje intelektiniam kapitalui vertinti deramo dėmesio neskiria nei verslo imonès, nei universitetai. Europoje kaip pavyzdinès šalys, kuriose sukurti pažangūs intelektinio kapitalo vertinimo modeliai, minimos Austrija, Švedija, Vokietija, Danija, Prancūzija, Ispanija, Islandija (Reporting Intellectual Capital to augment research $\langle\ldots>$, 2006, p. 12). Dažnai pateikiami vertingi IK vertinimo gerosios patirties pavyzdžiai iš Australijos, Kanados, Japonijos, Italijos (Bruggen, et al., 2009; Bozzolan et al, 2003; Williams, 2001). Taigi Lietuvoje turètų būti siekiama aktyviau perimti minètų šalių gerają patirtị ir kurti savają. Pavyzdžiui, Austrijoje nuo 2002 metų privaloma pateikti ataskaitas universitetams apie intelektinị kapitalą ${ }^{3}$. Austrija yra pirmoji pasaulyje šalis, paskelbusi IK vertinimą privalomą valstybiniams universitetams (Elena, 2009). Kai kuriose šalyse, pavyzdžiui, Japonijoje, Australijoje, pateikiamos gairès, pagal kurias organizacijos skatinamos savanoriškai teikti ataskaitas arba duomenis apie intelektinị kapitalą. Europos Komisijos iniciatyva suburta ekspertų grupé parengė RICARDIS (Reporting Intellectual Capital to augment $<\ldots>$, 2006) studiją, kuri skirta skatinti intensyviai žinias ku-

Prieiga internete: (http://www.uam.es/personal_pdi/economicas/palomas/THE\%20

INTELLECTUAL\%20CAPITAL\%20REPORT\%20FOR\%20UNIVERSITIES.pdf). 
riančias organizacijas (tiek viešas, tiek privačias) Europoje teikti ataskaitas apie intelektini kapitalą. Minèta studija unikali tuo, kad pateikia rekomendacijų, kaip potencialiems investuotojams suprasti ir interpretuoti IK vertinimus, o viešosios politikos kūrejjams - kaip skatinti organizacijas teikti duomenis apie IK. Minètas RICARDIS dokumentas pateikia IK vertinimo gaires ir aktualizuoja tai, kad IK vertinimas turètų būti plètojamas ne tik nacionaliniu, bet ir tarptautiniu mastu, siekiant didinti Europos konkurencingumą. Reikšminga IK vertinimo tarptautiniu mastu metodika yra 2004-2006 m. parengta Europos universitetų apžvalga (Observatory of the European University, OEU), kurioje nurodyti IK rodikliai. Tai bendras 15-os institucijų iš 8-ių Europos šalių darbas ${ }^{4}$. Beveik visi sutaria, kad IK vertinimas turi padèti tobulinti universitetų valdymą.

Investavimas ị žinių kūrimą, inovacijas vertinamas kaip vienas rizikingiausių, ypač kai kalbama apie mažas ir vidutines įmones, kurios Europoje sudaro didžiają dalị verslo sektoriaus (Reporting Intellectual Capital to augment research <...>, 2006). Todèl labai svarbu pateikti aukšto lygio ir patikimą informaciją, siekiant pritraukti investuotojų dèmesị ir pelnyti jų pasitikejimą. IK vertinimas, kai pateikiama organizacijos kuriamų žinių pridètinè vertẻ ir perspektyvumas, padètų intensyviau skatinti verslą ir daugiau investuoti ị mokslą.

\section{Išvados}

Intelektinio kapitalo formavimas visada buvo ir yra organiška universiteto veiklos dalis, todèl jo vertinimas buvo grindžiamas transcendentiniu požiūriu. Tačiau žinių visuomenėje aktualu universitetuose gerinti IK valdymą ir vertinimą, kuris remiasi vadybos kategorijomis. Tai ne tik padètų tobulinti universiteto kaip organizacijos valdymą, bet ir stiprintų jo verslumo bei inovacijų potencialą. IK koncepcija išplètota žinių ekonomikos kontekste, tačiau iš šių dienų perspektyvos svarbu dèl IK koncepcijos diskutuoti inovacijų kontekste. IK turètų būti suprantamas ne kaip rodiklis, o kaip organizacijos santykio su žiniomis koncepcija.

Intelektinio kapitalo vertinimas universitetuose yra problema, nes vertinimo modeliai nukreipti ị verslo įmonę. Pripažįstama, kad tokių verslo įmonės IK vertinimo modelių taikymas universitete galètų padèti tobulinti aukštojo mokslo ir studijų valdymą. Be to, tai padètų puoselèti darnaus mokslo ir verslo bendradarbiavimo aplinką. Vis dèlto būtina ieškoti specifinių universitetui, kaip produktyviam žinių kūrèjui, IK vertinimo modelių. Pastaruosius du dešimtmečius sparčiai vykdyti tarptautiniai ir nacionaliniai projektai, skirti analizuoti intelektinio kapitalo vertinimo universitetuose ypatumus ir kurti tam tinkamus modelius. Taigi univer-

4 Prieiga internete: http://www.eua.be/eua/jsp/en/upload/OEU2_abstract.1130771785459.pdf. 
sitetų IK vertinti sukurtas reikšmingas potencialas. Todẻl tik aktyvus pačių universitetų dalyvavimas gali padèti ši potencialą plètoti.

Intelektinio kapitalo nereikètų suprasti kaip savitikslio, konkrečiu dydžiu išmatuojamo dalyko. Nors IK vertinimo modeliuose siekiama išplètoti galimybes ivvardyti konkrečias kategorijas, tačiau tas vertinimas neturètų būti mechaniška žmogiškujų išteklių, žinių ir jų vadybos technologijų suma, o tarsi ekosistema, kurios esmę sudaro paskirų dalių jungimosi ị organišką visumą kokybinè charakteristika. Intelektinio kapitalo kokybinè charakteristika, straipsnio autorès požiūriu, yra socialinis kapitalas, kuris apima komunikaciją, nuostatas, vertybes, kurie nukreipia žmonių tarpusavio santykius kurti ekonominę ir socialinę gerovę. Šiuo požiūriu IK vertinimas tampa prasmingas, nes tiesiogiai koreliuoja su socialinio kapitalo stiprinimu ir plètote. Socialinis kapitalas gali būti traktuojamas kaip vienas svarbiausių IK plètotès veiksnių, ypač inovacijas kuriančioje visuomenejje.

Gauta 20140902

Pasirašyta spaudai 20140929

\section{Literatūra}

Andriessen, D. (2007). Designing and Testing an OD Intervention: Reporting Intellectual Capital to Develop Organisations. Journal of Applied Behavioral Science 43/1: 89-107.

Barnett, R. (2013). Imagining the university. New York: Routledge.

Bontis, N. (1998). Intellectual capital: an exploratory study that develops measures and models. Management Decision 36/2: 63-76.

Bozzolan, S., Favotto, F., Ricceri, F. (2003). Italian annual intellectual capital disclosure. An empirical analysis. Journal of Intellectual Capital 4/4: 543-558.

Bruggen, A., et al. (2009). Determinants of intellectual capital disclosure: evidence from Australia. Management Decision 47/2: 233-245.

Canibano, L., Sanchez, M. P. (2009). Intangibles in universities: current challenges for measuring and and reporting. Journal of Human Resource Costing \& Accounting 13/2: 93-104.

Chaharbaghi, K., Cripps, S. (2006). Intellectual capital: direction, not blind faith. Journal of Intellectual Capital 7/1: 29-42.

Drucker, P. F. (1993). Post-Capitalist Society, Butterworth Heinemann. Oxford.

Edvinsson, L. (1997). Developing Intellectual Capital at Scandia. Long Range Planning 30/1: 366-373.

Edvinsson, L., Malone, M. (1997). Intellectual Capital: Realizing Your Company's True Value by Finding its Hidden Brain-power. New York: Harper Collins, NY.

Elena, S. (2009). Intellectual Capital Approaches within higher education institutions: Lessons from Autonomous University of Madrid. In: M. S. van Geenhuizen et al. (eds.). Value-added Partnering and Innovation in a Changing. World Purdue University Press, p. 68-88.

Goldstein, S. M. et al. (2002). The service concept: the missing link in service design research? Journal of Operations Management 20: 121-134.

Gižienė, V., Barkauskas, V. (2010). Intelektinio kapitalo svarba universitetų valdymui. Ekonomika ir vadyba 15: 498-504.

Innovation Union Scoreboard. (2014). Prieiga internete: http://ec.europa.eu/enterprise/policies/innovation/files/ ius/ius-2014_en.pdf 
Ismail, M. B. (2005). The Influence of Intellectual Capital on the Performance of Telekom Malaysia. PhD Thesis. Universiti Teknologi Malaysia.

Kaplan, R. S., Norton, D. P. (1996). The Balanced Scorecard: Translating Strategy into Action. Boston: Harvard Business School Press.

Khalique, M. (2011). Intellectual Capital and Its Major Components. International Journal of Current Research 33/6, June: 343-347.

Laurs, I. (2013). Verslas naujai. Vilnius: Vaga.

Lietuvos mokslo būklès apžvalga. (2014). Vilnius: MOSTA.

Mačerinskienė, I., Bartusevičienè, I. (2012). İmonès intelektinio kapitalo vertinimo modelio taikymo ypatumai. Bussiness Systems and Economics 2 (2): 95-106.

Melnikas, B. ir kt. (2011). Žiniu ekonomikos kūrimas: inovaciju paramos sistema. Vilnius.

Mikulènienè, R., Jucevičius, R. (2000). Organizacijos intelektinis kapitalas: sandaros ir pagrindinių sąvokų interpretacijos. Socialiniai mokslai 3 (24): 65-75.

Meihami, B., Karami, J. (2104). The Relationship between Intellectual Capital Reporting and Universities Performance. MAGNT Research Report 2 (5):748-754.

Papula, J., Volná, J. (2011). Intellectual Capital as Value Adding Element in Knowledge Management. Proceedings of the International Conference Knowledge as Business Opportunity, Celje: 497-504.

Papula, J, Volná, J. (2012). A Content Analysis of Intellectual Capital Reporting within Slovak Companies. Proceedings of the European Conference on Intellectual Capital. Helsinki, Academic Publishing International, p. 363-370.

Pike, S., Roos, G. (2000). Intellectual capital measurement and holistic value approach (HVA). Prieiga internete: http://www.intcap.com/downloads/ICS_Article_2000_IC_Measurement_HVA.pdf

Ramírez Córcoles, Y. (2013). Intellectual capital management and reporting in European higher education institutions. Intangible Capital 9(1): 1-19. Prieiga internete: https://upcommons.upc.edu/revistes/bitstream/2099/13231/1/Intellectual\%20capital\%20management.pdf

Rastogi, P. N. (2003). The nature and role of IC: Rethinking the process of value creation and sustained enterprise growth. Journal intellectual capital 4/2. Prieiga internete: http://www.emeraldinsight.com/Insight/viewPDF. jsp?Filename=html/Output/Published/EmeraldFullTextArticle/Pdf/2500040208.pdf

Reporting Intellectual Capital to Augment Research, Development and Innovation in SMEs. (2006). Report to the Commission of the High Level Expert Group on RICARDIS. European Communities.

Roos, J., Roos, G., Dragonetti, N., Edvinsson, L. (1997). Intellectual Capital: Navigating in the New Business Landscape. New York: New York University Press, NY.

Sanchez-Canizares, S. M., Munoz, M. A. A., Lopez-Guzman, T. (2007). Journal of Intellectual Capital 8/3: 409-430. DOI 10.1108/14691930710774849

Sanchez, M. P. et al. (2009). Intellectual capital dynamics in universities: a reporting model. Journal of Intellectual Capital 10/2: 307-324.

Sussan, F. (2012). Consumer interaction as intellectual capital. Journal of Intellectual Capital 13/1: 81-105.

Stewart, T. A. (1997). Intellectual Capital: The New Wealth of Organizations. New York: Bantam Doubleday Dell Publishing Group, NY.

Sveiby, K. E. (2001). Methods for measuring intangible assets. Prieiga internete: http://www.sveiby.com/Portals/0/articles/IntangibleMethods.htm

Sveiby, K. E. (1997). The New Organizational Wealth: Managing and Measuring Knowledge-based Assets. San Francisco: Berret-Koehler Publishers Inc.

The Culture of Innovations and the Building of Knowledge Societies. (2003). Issue Paper. UNESCO, Bureau of Strategic Planning.

Valantiejus, A. (2007). Sociologijos istorija. Sociologijos filosofija, t. 1. Vilnius: VU leidykla.

Williams, S. M. (2001). Is intellectual capital performance and disclosure practices related? Journal of Intellectual Capital 2/3: 192-203. 


\section{INTELLECTUAL CAPITAL AS POTENTIAL TO STRENGTHEN COOPERATION BETWEEN SCIENCE AND BUSINESS}

\section{Rita Vaičekauskaitė}

\section{Summary}

Intellectual capital (IC), technology transfer, knowledge management gained a high topicality in knowledge-based economy. The aforementioned concepts emerged in a business world to show competitive advantage of enterprise in a knowledge-based economy. Identification of IC was oriented to demonstrate that enterprises are concerned with knowledge creation and not solely with financial accounting. On the contrary, IC is organic entity of university life. However, in nowadays society universities should transform IC into competitive advantage; therefore, it is important to evaluate IC at universities using management categories. The article aim to reveal the potential of IC to strengthen cooperation between science and business. Research methods are systemic literature analysis, meta-analysis of research data. The paper derives theoretical predictions from the scientific literature and already existing data. Despite an increasing stream of research on intellectual capital, we lack clear results on management and disclosure of IC. Moreover, IC concept developed in a knowledge-based economy context, but now-days we need reconsider IC in innovations context. Innovations are not only about knowledge development, it is more about people's reflective relationship with them. Reporting on IC could help to build reflective relationship with knowledge we create.

The problem is the lack of conceptual cooperation between science and business. Certain data indicates the aforementioned problem. Recently Lithuania is among moderate innovators ${ }^{5}$, however, estimating the economic impact of innovations Lithuania stands in the last position among EU countries (Lietuvos mokslo būklès apžvalga, 2014, p. 7). Theoretical analysis empower to imply that IC enable for creating conceptual cooperation. We are too much concentrated on offering services instead of talking of conceptual understanding that is important for cooperation oriented towards innovations. Cooperation based on innovations needs broader horizons therefore R. Barnett (2013) makes very accurate pointing out that now-days university are suffering due to lack of imagination.

Prieiga internete: http://ec.europa.eu/enterprise/policies/innovation/files/ius/ius-2014_en.pdf, p. 11. 
The first section of the article develops discussion on the structure of IC concept. The structure of IC enables for knowledge operationalization in three categories (Papula, Volna, 2012, p. 364):

- Human Capital: skills, knowledge inside the person.

- Organizational Capital: skills, knowledge oriented outside the person and inside the company.

- Relational Capital: skills, knowledge oriented outside the person and outside the company.

The article author emphasizes that structure of IC is not the sum of three aforementioned parts, but an eco-systemic unit with new quality. Theoretical preconditions enable to state that social capital unifies three different parts of IC into new entity with the highest quality.

The second section of the article develops discussion on the models for IC evaluation. Mainly models of IC evaluation and reports are oriented for business enterprises. Therefore, universities are in great lack for specific models for IC evaluation. The article introduce the main objectives of joint projects such as MERITUM, 2002; RICARIS, 2006; Observatory of the European University, 2004-2006 that consider for IC report issue at universities. Multi-complex project RICARDIS provides with complex guidelines for different institutions. Firstly, it provides guidelines for research-intensive SME's on reporting on their intellectual capital. Secondly, RICARDIS provides with recommendations for investors and private stakeholders on how to interpret and value intellectual capital statements and how to encourage companies to report on their intellectual capital. Thirdly, recommendations for public policy makers on how to stimulate companies to report on their intellectual capital (Reporting Intellectual Capital to augment research $<\ldots>$, 2006). RICARDIS imply for need to systematic point of view towards IC. Many investigators agree that there is a need for specific models for evaluation of IC at universities. However, there is agreement that using the same models as in business enterprises for IC evaluation at universities cold help to improve management system at universities. Moreover, the experience of implementing of total quality management systems in Lithuanian universities in recent five years demonstrate positive effect for management improvement at universities.

Universities are in great pressure for knowledge commercialization. Therefore, IC should be evaluated in management categories. However, IC evaluation should not be confused with estimation in money. IC has to represent organization's relationship with knowledge concept instead of finding out a fixed index. IC repor- 
ting meaning serves for those who are thinking about long lasting cooperation and long lasting investments. Investments in $\mathrm{R} \& \mathrm{D}$ and innovation are intangible investments per se, which entail greater risk and uncertainty than other investments (Reporting Intellectual Capital to augment research $<_{\ldots} .>$, 2006, p. 10). For innovations, it is important potential for strategic and long lasting cooperation (The Culture of Innovations and the Building <...>, 2003). IC helps to demonstrate the unique potential. 
